\title{
Pobrecitos jovencitos sin sexo y sin seso. Formas y modelos de vida estudiantil bajo la crítica de los reformistas de izquierda en la Universidad de Buenos Aires (1917- 1921)
}

\section{Poor young men without sex and brain. Manners and Models of Student Life Under the Left-Wing Reformist Critic in the University of Buenos Aires} (1917- 1921)

\author{
Luciana Carreño*
}

\begin{abstract}
Resumen
El presente trabajo se centra en reconstruir la sociabilidad estudiantil en la Universidad de Buenos Aires entre 1917- 1921. Se busca indagar sobre la implementación de la Reforma Universitaria en esa casa de estudios que concentraba más de la mitad de la población universitaria del país. Para ello se recurrirá a publicaciones de grupos reformistas de izquierdas quienes, desde sus revistas, interpelaron a las juventudes universitarias a fin a reformular sus prácticas y modos de asociarse y de socializar un nuevo perfil estudiantil.

Palabras Clave: Reforma universitaria, sociabilidades, vida estudiantil, renovación educativa

Abstract

The work at hand focuses on the reconstruction of student sociabilities at the University of Buenos Aires (UBA) between 1917-1921. It aims to inquire into the implementation of the University Reform and the effect it had on the capital's collegial student body, which concentrated more than half of the universitary population in the country. To achieve this purpose, the present paper will resort to analyzing publications written by left-wing reformists who, by means of their reviews, interpellated university youths to reformulate their practices, their ways of associating, and to socialize a new student profile.
\end{abstract}

Key Words: University Reform, sociability, Student Life, educational renewal.

Recibido: 11 octubre 2016

Aceptado: 18 diciembre 2016

\footnotetext{
*Argentina, Universidad Nacional de Quilmes (UNQ), Concejo Nacional de Ciencia y Tecnología (CONICET), Centro de Estudios en Historia, Cultura y Memoria (CEHCMe), Buenos Aires, Argentina. lcarreno1@uvq.edu.ar. Este trabajo se desarrolló en el marco del proyecto: "Universitarios, Artistas e intelectuales en la Argentina. Prácticas culturales, producción de saber y modos de intervención política, 1900-1975" que dirige el Dr. Osvaldo Graciano dentro del CEHCMe. Agradezco a los evaluadores de la revista Izquierdas por sus comentarios y observaciones.
} 
Como movimiento de alcance latinoamericano, la Reforma Universitaria puso en escena el protagonismo de las juventudes estudiantiles que, en los distintos países de la región, se constituyen como uno de los actores políticos del periodo. En el caso argentino, dicho proceso tiene como episodio central la movilización de los estudiantes de la Universidad de Córdoba en 1918 que condujo a la intervención de esa casa de estudios y a la reforma de los estatutos de todas las universidades del país. Sin embargo, este proceso no se replicó de manera homogénea y adquirió características propias en cada uno de los escenarios en los cuales la Reforma fue implementada. El enfoque que se propone en este trabajo pretende iluminar ese proceso en relación a un tema y a un actor en particular: la sociabilidad del estudiantado de la Universidad de Buenos Aires (UBA), centro que albergaba a más de la mitad de la población universitaria del país ${ }^{1}$.

En el contexto argentino de la segunda década del siglo XX, el movimiento de la Reforma Universitaria supuso por parte de los estudiantes y profesores que lo promovieron una serie de críticas y demandas que concernían tanto a aspectos pedagógicos y del gobierno universitario como a cuestiones políticas y sociales que excedían los límites de la institución académica. En paralelo a estos cuestionamientos, el presente trabajo se propone analizar cómo también esas críticas interpelaron a la juventud universitaria y permearon cotidianamente la vida y la sociabilidad estudiantil.

Desde principios de siglo, en la ciudad de Buenos Aires, los centros estudiantiles se perfilaron como uno de los principales espacios de sociabilidad donde, además de la representación gremial de los asociados, se difundieron diversos modelos de vida estudiantil que circulaban también entre las juventudes latinoamericanas de la época. Sin embargo, tal como estudiaremos, tanto el perfil gremial y profesional que acompañaba a estas asociaciones, como otros temas de la vida estudiantil en su conjunto fueron objeto de una revisión crítica por parte de distintas publicaciones identificadas con la Reforma. En este sentido, se puede advertir una serie de cuestionamientos sobre los modos y comportamientos que (en materia de prácticas recreativas y deportivas) caracterizaban la vida de los universitarios y, por otro lado, se observa un conjunto de críticas sobre asuntos educativos que implicaban la participación estudiantil (formas de estudiar, de asegurar la calidad de la enseñanza, entre otras cuestiones) y que hacían a la renovación universitaria que perseguían los estudiantes reformistas. A partir de ello, se considera que el análisis de estas críticas contribuye a la comprensión del proceso de democratización de la universidad emprendida por los estudiantes del movimiento reformista. En este sentido, dicho proceso no habría tenido por objeto solamente la participación estudiantil en el gobierno universitario o la obtención de la docencia libre, sino que también, de un modo más horizontal, aspiró a reformar las conductas y las formas sociales que caracterizaban la vida estudiantil de la época y a sociabilizar un nuevo perfil de estudiante.

\footnotetext{
${ }^{1}$ Hacia 1910, la UBA albergaba al 78\% de los seis mil alumnos matriculados en las universidades argentinas, el resto se repartía entre las dos universidades existentes, la de Córdoba con el $8 \%$ y la de La Plata con el 14\%. Adriana Chiroleau, "La Reforma Universitaria", Falcón, R. (dir.), Nueva Historia Argentina. Democracia, conflicto social y renovación de ideas, Buenos Aires, Sudamericana, 2000, 363.
} 
El periodo en cual se inscribe este estudio se enmarca dentro de un proceso de cambios que se operaban en la universidad porteña desde principios de siglo. Dichos cambios no solamente se expresaron a nivel político, en la oposición estudiantil hacia ciertas autoridades académicas que, pese a las modificaciones establecidas en la reforma de los estatutos de 1906, continuaban asociadas a los grupos tradicionalmente gobernantes, sino también en el peso creciente de la masa estudiantil en la vida universitaria ${ }^{2}$. En ese último sentido, el aumento progresivo del alumnado en las primeras décadas del siglo alteró la composición social de la universidad que comenzó a albergar a los hijos de las clases medias de origen inmigratorio. Esa nueva situación generó elementos de conflicto a raíz del reconocimiento político, social y cultural que exigían los sectores recién llegados a la universidad $^{3}$. Asimismo, según señala Losada para el caso argentino, los hijos de las familias más encumbradas no contaban con instituciones educativas exclusivas o restringidas a la hora de cursar sus estudios superiores ${ }^{4}$. De este modo, el crecimiento de la matrícula implicó una situación de convivencia inédita dentro de la universidad.

A diferencia de los demás centros universitarios nacionales, como Córdoba y La Plata, Buenos Aires no contaba con una comunidad estudiantil diferenciada del resto de sus habitantes. En ese contexto, las interpelaciones a seguir el "ejemplo de Córdoba" que realizaron los reformistas de Buenos Aires se explican tanto por el ambiente de cosmopolitismo y dispersión que caracterizaba a la metrópolis porteña, como por el hecho de que en aquella ciudad la Reforma universitaria no se logró luego de una masiva acción estudiantil, sino que se impuso directamente por la intervención de las autoridades nacionales. De este modo, los reformistas porteños enfatizaban que la Reforma, acaecida por decreto, debía ser acompañada por nuevas actitudes y prácticas estudiantiles.

En base a estos objetivos recurrimos a publicaciones de la prensa estudiantil porteña analizando un corpus integrado por las revistas Themis. Revista del Centro de Estudiantes de la Facultad Derecho y Ciencias Sociales (1918-1920) y La Cureta. Órgano de la Agrupación de Estudiantes de Medicina "Pro Reforma" (1918-1921). Ambas estaban relacionadas con dos de las Facultades que representaban al grueso del alumnado universitario y permiten analizar cuestiones propias del ambiente estudiantil en esas carreras. Finalmente, completaremos nuestro análisis con documentos del periodismo político universitario a través de las publicaciones Ideas y Clarín del Ateneo de Estudiantes Universitarios y del periódico Bases. Tribuna de la juventud (1919-1920) dirigido por Juan Antonio Solari. Como se advierte si bien estas publicaciones representaban distintos sectores del periodismo universitario, tal como ha estudiado Bustelo, todas ellas comparten

\footnotetext{
${ }^{2}$ Estas reformas, acaecidas en 1906, supusieron la modificación de los cuerpos directivos. A partir de esto, los cargos dejaron de ser vitalicios y elegidos internamente por el mismo cuerpo académico, para dar lugar a consejos renovables y elegidos en base a una terna elaborada por profesores mediante una asamblea. Cf. Tulio Halperín Donghi, Historia de la Universidad de Buenos Aires, Buenos Aires, Eudeba, 2012, [1962], 93- 103. ${ }^{3}$ Adriana Chiroleau, Op Cit., 365-369.

${ }^{4}$ Ello los diferenciaba por ejemplo de grupos sociales semejantes de otros países que, ante la ampliación del acceso a la educación que supuso la modernidad, contaban con instituciones educativas (como las public schools británicas) que resguardaban un importante nivel de admisión definido en criterios tanto intelectuales como económicos. Cf. Leandro Losada, La alta sociedad en la Buenos Aires de la Belle Époque, Buenos Aires, Siglo XXI, 2008, 107- 108.
} 
el posicionamiento común de alinearse a favor de la vinculación del movimiento estudiantil con el movimiento obrero en contraposición con otras revistas y grupos que, dentro del reformismo, apoyaron una postura nacionalista contraria a esa reivindicación. Asimismo, a diferencia de otras publicaciones juveniles de izquierda del periodo, más enfocadas en la difusión de artículos doctrinarios y notas de actualidad, el conjunto seleccionado resulta elocuente y rico en alusiones para analizar los temas de sociabilidad y vida estudiantil que abordamos en este estudio 5 .

El énfasis crítico, aunque algunas veces permisivo, que se utilizaba en estos escritos para interpelar a la juventud universitaria nos invita a retomar el enfoque propuesto por Bisso a la hora de explicar los cruces entre la sociabilidad y la política. Estos grupos, si bien sus miembros no estaban afiliados homogéneamente a un partido político, se inscriben, como ya hemos advertido, dentro de un posicionamiento de izquierda al saludar el advenimiento de la Revolución Rusa, la "Internacional del pensamiento" promovida por Henri Barbusse y al apelar a la vinculación del movimiento estudiantil con la clase obrera. En este sentido, tal como ha señalado Bisso, las formas de sociabilidad y ocio pueden ser un observatorio desde el cual entender la simpatía ideológica en aspectos que, si bien son más cotidianos, resultan menos visibles en la plataforma formal de la retórica o del discurso ${ }^{6}$. Para ello, se considerarán los aportes historiográficos que han estudiado a los actores del movimiento de la Reforma Universitaria desde su dimensión ideológica y desde el papel que les cupo como intelectuales y actores políticos del periodo ${ }^{7}$.

Al abordar estas cuestiones recurriremos a los aspectos que Maurice Agulhon señalaba dentro del estudio de la sociabilidad como categoría histórica ${ }^{8}$. Por un lado, utilizaremos este concepto en tanto marco de observación y clasificación de lo intersocial cotidiano lo cual permite analizar e identificar los hábitos y prácticas de vida estudiantil que se ponen en circulación en un determinado contexto histórico. En este sentido, las críticas de los reformistas porteños permiten visibilizar estas cuestiones que se sitúan dentro y fuera de los marcos asociativos y de la esfera universitaria. No obstante, ello no supone dejar de lado los aspectos asociativos de la vida estudiantil lo cual constituye el segundo punto de nuestro análisis ${ }^{9}$. De este modo, se buscará estudiar las dinámicas de la vida social que se

\footnotetext{
${ }^{5}$ Dentro del ámbito porteño y del periodismo juvenil de izquierda se citan además a Via Libre. Publicación de Crítica Mensual (1919-1922) y la revista universitaria Insurrexit (1920- 1921). Cf. Natalia Bustelo, La reforma universitaria desde sus grupos y revistas. Una reconstrucción de los proyectos y las disputas del movimiento estudiantil porteño de las primeras décadas del siglo XX (1914- 1928), FaHCE. Universidad Nacional de La Plata, 2015, 15-16. (Tesis de doctorado inédita).

${ }^{6}$ Andrés Bisso, Sociabilidad, Política y movilización: cuatro recorridos bonaerenses 1932-1943, Buenos Aires, Buenos Libros, 2009, 70.

${ }^{7}$ Juan Carlos Portantiero, Estudiantes y política en América Latina. El proceso de la reforma universitaria (1918 -1938), México, Fondo de Cultura Económica, 1978; Osvaldo Graciano, Entre la torre de marfil y el compromiso político. Intelectuales de izquierda en la Argentina, 1918- 1955, Bernal, Universidad Nacional de Quilmes, 2008 y Natalia Bustelo. Op. cit.

${ }^{8}$ Maurice Agulhon, "La sociabilidad como categoría histórica", AA.VV., Formas de sociabilidad en Chile 1840-1940, Santiago de Chile, Fundación Mario Góngora, 1992, 1-10.

${ }^{9} \mathrm{Al}$ considerar la vida cotidiana y asociativa como dos puntos de análisis no se pretende adoptar un enfoque dicotómico que oponga la sociabilidad formal e informal al considerar que ambas formas se relacionan en las
} 
desarrollan en torno a estas asociaciones (grupos editoriales, centros y de estudiantes, clubes estudiantiles) las cuales se especifican de forma particular según cada grupo y sector social $^{10}$. En este sentido, si bien el fragmento temporal señalado para nuestro análisis se centra en un corto periodo que se inicia entre 1917 y 1918, se considerarán elementos de la sociabilidad estudiantil desde principios de siglo con el fin de analizar las prácticas y modelos que circulaban entre los universitarios de la región y de brindar un marco histórico desde el cual observar tanto los continuidades como las reformulaciones que los reformistas porteños proponen a estas formas sociales. Finalmente, el estudio de la sociabilidad permite señalar elementos de identificación colectiva los cuales se definían en relación a otras prácticas y grupos estudiantiles. En base a ello se analizarán las nociones, los modelos y los valores normativos de la vida estudiantil que los actores ponían en discusión o que intentaban implementar y que no siempre tenían la respuesta esperada entre los estudiantes ${ }^{11}$.

Si bien desde finales del siglo pasado la sociabilidad se ha constituido como objeto de indagación historiográfica, su estudio en relación a los estudiantes universitarios aun presenta un margen para la investigación ${ }^{12}$. En este sentido, se considera que su abordaje aporta elementos de relevancia que, desde una perspectiva histórica, contribuyan al análisis de estos actores sociales desde su condición juvenil y su movilización colectiva ${ }^{13}$.

funciones socioculturales que desempeñan. Cf. Javier Escalera, "Sociabilidad y relaciones de poder", Kairos, Universidad Nacional de San Luis, año 4, nº 6, 2000.

${ }^{10} \mathrm{La}$ especificad social de las formas de sociabilidad conforma otro de los puntos trabajados por Agulhon en sus estudios de sobre las formas de sociabilidad propiamente burguesas (con el surgimiento de los círculos en oposición a los salones como forma aristocrática y jerárquica) y obreras (la chambreé, el cabaret y la apropiación obrera de los círculos). Maurice Agulhon, El círculo burgués. La sociabilidad en la Francia, (1810-1848), Buenos Aires, siglo XX, 2009, [1977] y Maurice Agulhon, "Clase obrera y sociabilidad antes de 1848”, Maurice Agulhon, Historia Vagabunda. Etnología y política en la Francia contemporánea, México, Instituto Mora, 1994, [1988], 54-85.

${ }^{11} \mathrm{Se}$ considera importante la contextualización de estas nociones lo cual apunta a evitar el anacronismo que supone naturalizar el concepto de sociabilidad, dada el sentido programático y normativo que tenía este neologismo en la época. Cf. González Bernaldo de Quirós, Pilar, "La sociabilidad y la historia política", Nuevo Mundo Mundos Nuevos, 2008.

${ }^{12}$ Para un estado de la cuestión véase entre otros: Javier Navarro Navarro, "Sociabilidad e historiografía: trayectorias, perspectivas y retos", Saitabi, 56, Valencia, 2006, 99 - 119. En relación al tema estudiantil algunos de los estudios citados en este trabajo abordan la cuestión, en especial el trabajo de SebastiánGerardo Fuentes "Un club para "nosotros" en la reforma del 18. Sentidos de la universidad y la nación en lo jóvenes universitarios no reformistas", Revista iberoamericana de Educación Superior (RIES), vol. VII, n 18, México, UNAM_ISSUE/Universia, 2016, 60-81 y desde la historia intelectual: Natalia Bustelo, "La juventud universitaria de Buenos Aires y su vínculo con las izquierdas en los inicios de la Reforma Universitaria (1914-1922)", Revista Izquierdas, 16, Santiago de Chile, 2013, 1-30.

${ }^{13}$ Según Vommaro las prácticas asociativas y contexto de socialización (en el cual una cohorte se apropia, y al mismo tiempo resignifica, las prácticas sociales y políticas en el mundo en que habita) forman parte de uno de los aspectos que se consideran en la reelaboración que, desde la ciencia sociales, se le ha hecho en torno a los conceptos de juventudes (como una construcción social y no como una condición meramente etaria o una caracterización esencialista) y de generación (definida no como una contemporaneidad cronológica sino como un concepto que incluye entre otros factores los criterios de identificación común y las dinámicas políticas, sociales y culturales de las sociedades en las que se producen). Pablo Vommaro, Juventudes y políticas en la Argentina y en América Latina. Tendencias, conflictos y desafios. Grupo Editor Universitario, Buenos Aires, 


\section{Sociabilidad estudiantil desde principios del siglo XX}

Desde comienzos del siglo XX, se registran distintas prácticas y escenarios de sociabilidad estudiantil que, de modo común, identificaron a los estudiantes sudamericanos. En la región estas prácticas se socializaban a través de intercambios de publicaciones, torneos atléticos, visitas recíprocas de delegaciones estudiantiles, entre otras formas. Sin embargo, los Congresos Internacionales de Estudiantes Americanos reunidos en Montevideo (1908), en Buenos Aires (1910) y en Lima (1912) se destacan como una de las principales instancias de interacción estudiantil dados los lazos organizativos que se crean en estos encuentros en los cuales coincidieron universitarios de distintos países de la región. La realización de estos congresos, que surgen a partir de la iniciativa de los estudiantes uruguayos, ha sido abordada por distintos autores quienes han analizado los temas debatidos (renovación de los métodos de enseñanza; extensión universitaria; cogobierno estudiantil; libertad de estudios; entre otros) destacando que muchas de estas propuestas integrarían posteriormente el programa de reformas emprendidas en 1918 a partir del movimiento cordobés ${ }^{14}$.

Sin embargo, más allá de la agenda de reformas que se señalan tempranamente en estos congresos, en el contexto de este trabajo estos eventos pueden interpretarse como espacios de sociabilidad en los cuales los universitarios de la región discutieron y reafirmaron prácticas, valores y modelos de comportamiento e identidad propiamente estudiantiles. En primer lugar, una de estas prácticas comunes se relaciona con la elección del congreso como formato de los encuentros con lo cual los estudiantes adoptaban uno de los modos de producción intelectual y científica de gran difusión en esa época. El congreso como práctica de organización estudiantil, de larga tradición entre los universitarios europeos, se inaugura posiblemente en el ámbito latinoamericano con el Primer Congreso

2015. Sobre este tema véase entre otros Pierre Bourdieu, "La juventud no es más que una palabra", Sociología y cultura, México, Grijalbo, 1990; Enrique Martín Criado, "Generación/Clase de edad", Román Reyes (Dir.) Diccionario Crítico de Ciencias Sociales, Madrid y México, Ed. Plaza y Valdés, 2009.

${ }^{14} \mathrm{~A}$ partir de este punto, algunos autores han cuestionado la excesiva importancia que se le ha otorgado a la fecha de 1918 señalando que la Reforma Universitaria surgió efectivamente más atrás como un proceso gradual en cual el Congreso de Montevideo contribuyó de modo sustancial. (Cf. Mark Van Aken, Los militantes. Una historia del movimiento estudiantil universitario uruguayo desde sus orígenes hasta 1966, Montevideo, Fundación cultura universitaria, 1990., 42 y Mark Van Aken, "University Reform before Córdoba", Hispanic American Historical Review, vol. 51, no. 3, 1971, 447-462). Por otra parte, el historiador chileno Maraga Valle, al analizar estos congresos y la historia del movimiento estudiantil chileno ha cuestionado la interpretación historiográfica que plantea la "expansión" del movimiento de la Reforma Universitaria desde Córdoba hacia el resto de Latinoamérica, destacando la necesidad de estudiar cada proceso de modo particular (Fabio Moraga Valle, "Muchachos casi silvestres". La Federación de Estudiantes y el movimiento estudiantil chileno. 1906-136, Santiago de Chile, Ediciones de la Universidad de Chile, 2007. Asimismo, distintos autores uruguayos han estudiado y destacado la importancia de estos congresos sin plantear cuestionamientos en relación a la relevancia del movimiento cordobés de 1918. Véase: Juan Odonne y Blanca Paris, Historia de la Universidad de la República. Tomo II, La universidad del militarismo a la crisis 1885- 1958, Montevideo, Ediciones universitarias, 2010, [1971], 91-146; Emilio Landinelli, El movimiento estudiantil en el Uruguay. Primera parte. De los orígenes a la conquista de la Ley Orgánica de 1958. México, FLACSO, 1983; Vania Markarian, María Eugenia Jung, Isabel Wschebor, 1918. Una hora americana. Vol II, Universidad de la República, 2008. 
de Estudiantes Centroamericanos, reunido en Guatemala en $1901^{15}$. A partir de allí este dispositivo tendrá un largo derrotero en los distintos congresos estudiantiles nacionales y obtendrá una mayor proyección continental con la realización del Primer Congreso Internacional de Estudiantes celebrado en México en $1921^{16}$.

Por otra parte, estas reuniones actúan como lugares de intercambio en los cuales se reafirma la condición estudiantil, como un status diferenciado dentro de la sociedad, mediante la construcción de un ethos y la implementación de símbolos identitarios. Entre estos se destaca la designación del primer día de la primavera como "día del estudiante americano" "17 la cual llegaría a implementarse como una festividad estudiantil en varios de los países de la región, mientras que otros distintivos (como el himno y la capa estudiantil discutidos en el congreso de Lima) no lograrían tener el mismo éxito. Asimismo, estos encuentros promovieron modelos de sociabilidad en torno al desarrollo de la cultura física (se organizan torneos internacionales de atletismo), la educación moral y el fomento de la cultura cívica de los universitarios (temas que se discuten en el segundo congreso) ${ }^{18}$. Algunos de estos modelos se inspiraban en formas de sociabilidad de los estudiantes europeos con los cuales los estudiantes sudamericanos mantenían contacto por medio de la adhesión a la Federación Internacional de Estudiantes (FIDE Corda de Frates) o por medio de los viajes que algunos de estos jóvenes de familias más acomodadas emprendían por el viejo continente. Finalmente, este ethos de la juventud contó con una elaboración simbólica en la obra Ariel del uruguayo Enrique Rodó que comienza a difundirse a partir del congreso de Montevideo.

Asimismo, estos congresos resultan representativos de las vinculaciones socio políticas de esta juventud de principio de siglo. En este sentido, tal como ha demostrado Susana García, estos encuentros fueron patrocinados y apoyados económicamente por distintos gobiernos latinoamericanos dentro de una política de relaciones exteriores en la cual se proyectaba para los estudiantes el papel de "embajadores intelectuales"19. Al mismo tiempo, estas vinculaciones políticas (que también eran aprovechadas por los estudiantes para llevar adelante sus proyectos y demandas) se explican dada la extracción social de muchos de los congresistas la cual los ubica, en muchos casos, en continuidad antes que en

\footnotetext{
${ }^{15}$ En este congreso, además de los aspectos académicos y de modernización pedagógica, se plantean ideas que tendrán resonancia en décadas posteriores: la necesidad de unión estudiantil centroamericana y la vinculación del estudiantado con todos los grupos de la sociedad. CF Virgilio Alvarez Aragón, Conventos Aulas y trincheras. Universidad y movimiento estudiantil en Guatemala. Vol. 1, Guatemala, FLACSO, 2002,143- 148.

${ }^{16}$ Sobre los distintos congresos estudiantiles nacionales e internacionales véase: Roberto Machuca Becerra, América Latina y el Primer Congreso de estudiantes de 1921, tesis de licenciatura, México, UNAM, 1996.

17 "Relación oficial del Primer Congreso internacional de Estudiantes Americanos, Evolución, t. III, año III, $\mathrm{n}^{\mathrm{o}}, 21,22,23$ y 24, marzo- junio, Montevideo, 1908, 162.

18“Relación oficial del segundo Congreso Internacional de Estudiantes Americanos celebrado en Buenos Aires de 9 a 16 de julio de 1910”, Buenos Aires, Tall. Gráf. de la Penitenciaría Nacional, 1912. 86- 110.

${ }^{19}$ Susana García, “Embajadores intelectuales'. El apoyo del Estado a los Congresos de estudiantes americanos a principios del siglo XX”, Estudios Sociales, año, X, n 19, Santa Fe, 2000, 65- 84.
} 
disidencia con las elites sociales y políticas de los regímenes oligárquicos que predominaban en la región ${ }^{20}$.

Finalmente, estos congresos revelan una maduración de las formas asociativogremiales propiamente estudiantiles que comienzan a desarrollarse en los distintos países desde finales del siglo XIX. Tal como analiza Sabato para el caso argentino, en la segunda mitad de ese siglo el desarrollo de las asociaciones acompañó un doble proceso que supuso al mismo tiempo la construcción y consolidación de Estado y la formación de una sociedad civil relativamente autónoma. En ese contexto, las asociaciones y especialmente las de profesionales (donde también se puede incluir a las incipientes organizaciones estudiantiles) ocupan un rol en ese proceso de consolidación social al asumir una misión civilizatoria que resultaba, por lo general, acorde con las políticas del estado ${ }^{21}$. En relación a los universitarios, esta misión civilizatoria, acompañada en algunos casos por una representación que ubicaba a los estudiantes como futuros miembros de la clase dirigente, puede identificarse junto a las preocupaciones cívicas y sociales que comienzan a implementar las asociaciones estudiantiles mediante la promoción de la extensión universitaria $^{22}$.

En la Argentina, estas prácticas de sociabilidad se desarrollan, entre otros ámbitos, al interior de los centros de estudiantes. En la ciudad de Buenos Aires desde principios de siglo, el alumnado de la UBA había conseguido su organización gremial con la creación de los centros de estudiantes de las principales Facultades y, en 1908, de la Federación Universitaria de Buenos Aires (FUBA) que congregaba a dichas organizaciones. Como espacios de interacción, esas instancias asociativas brindaban un ambiente de sociabilidad para los jóvenes que acudían a la universidad de la gran metrópolis porteña que, a diferencia de otras ciudades, no contaba con un campus universitario y se caracterizaba por la dispersión de sus sedes de estudio ${ }^{23}$.

Tal como mencionamos, dentro de los centros circularon distintos modelos de sociabilidad estudiantil que identificamos en relación a los congresos: actividades

\footnotetext{
${ }^{20}$ Martín Bergel, “América Latina, pero desde abajo. Prácticas y representaciones intelectuales de un ciclo histórico latinoamericanista. 1898-1936, Cuadernos de Historia, n 36, junio 2012, Universidad de Chile, 7 36.

${ }^{21}$ Hilda Sabato, "Estado y sociedad civil", Elba Luna y Elida Cecconi (coord.). De las cofradías a las organizaciones de la sociedad civil. Historia de la iniciativa asociativa en la argentina 1776- 1990, Argentina, Edilab, 2012, 101- 170.

${ }^{22}$ En esta materia se advierte diferencias entre las distintas organizaciones, tal como plantea Moraga Valle, mientras los universitarios rioplatenses estaban más preocupados por la democratización de las estructuras universitarias, los chilenos aportaron más énfasis en las políticas sociales a las cuales se habían orientado desde principios de siglo, especialmente los estudiantes de medicina, con la creación de las Escuelas nocturnas para obreros en donde se impartían lecciones de higiene. Sin embargo, este autor señala que en esta instancia esas preocupaciones sociales decantaron en iniciativas principalmente asistencialistas. Fabio Moraga Valle, "Muchachos... op. cit., 69- 70 y 95.

${ }^{23}$ Esta diferencia se advierte con la vecina Universidad Nacional de La Plata (UNLP) cuya organización preveía la integridad del sistema educativo lo cual propiciaba una relación de los alumnos en todos los ciclos de enseñanza y se materializaba en la idea de campus universitario y la creación de un internado. Asimismo, la sociabilidad estudiantil en la UNLP se favorecía por la correlación de los estudios que establecía la rotación de los alumnos por las facultades para cursar materias comunes. Cf. Patricia Funes, Escenas reformistas, La reforma universitaria 1918-1930, Buenos Aires, Eudeba, 1998, 59.
} 
deportivas, promoción de la cultura cívica y la reafirmación de una identidad propiamente estudiantil a través de los símbolos y de las actividades que patrocinaban (entre las que se destacaron principalmente los estandartes, medallas y botones y la organización de torneos y comidas en distintos restaurantes de la ciudad). No obstante, dada la multiplicidad de fines que cumplían estas asociaciones las iniciativas de los centros por socializar determinadas costumbres y modelos de vida estudiantil no siguieron una pauta común. Si bien se registran instancias que excedían las cuestiones gremiales y proponían una intervención de los estudiantes en cuestiones ajenas a su especialidad (tales como la extensión universitaria que comenzó a aplicarse en 1915 bajo el patrocinio de la FUBA ${ }^{24}$ ) estas resultaron minoritarias e insuficientes para definir un perfil estudiantil con compromiso social o con inquietudes culturales por fuera los límites de la institución gremial.

Sin embargo, este tipo de intereses sí caracterizó a otras agrupaciones que, en la misma época, congregaban al estudiantado universitario. Entre éstas Bustelo ha reconstruido distintas redes de sociabilidad estudiantil animadas por diferentes afinidades culturales y políticas, identificando así la red de estudiantes católicos; la red del socialismo científico (reunida en torno a los Centros Ariel, la Universidad Libre y la Federación de Asociaciones Culturales), y por otro lado la red del idealismo estético tramada por el Ateneo Universitario (y su revista Ideas) y el Colegio Novecentista. Esta autora señala que, a partir de las actividades de estos grupos surge una primera identidad estudiantil preocupada por cuestiones culturales que excedían los asuntos meramente profesionales y gremiales. Sin embargo, con el estallido y articulación de la Reforma, se reconfigura este mapa ya que además de aparecer nuevos grupos identificados con el socialismo bolchevique, la oposición cultural entre la matriz estética y científica pierde peso en la medida que la toma de postura en la cuestión social, delimitada dentro del contexto de la Revolución Rusa y el ciclo de protestas obreras de inicios de 1919, se perfiló como tema de discusión que dividió a las agrupaciones del reformismo ${ }^{25}$.

Es en ese contexto, tal como estudiaremos en los siguientes apartados, en el cual los centros empiezan a ser objeto de crítica y de propuestas de reformulación. Dentro de este mapa juvenil, al que aludimos arriba, el grueso del alumnado universitario, agremiado o no dentro de los centros, figura como el destinatario que se interpela en las publicaciones que analizamos, las cuales si bien representan a grupos minoritarios lograrán acceder (en el caso de los editores de Themis y La Cureta) a la conducción de los centros estudiantiles. Asimismo, este amplio público era disputado por otras agrupaciones estudiantiles que buscaban inscribir a la Reforma desde un ideario nacionalista opuesto a las reivindicaciones de izquierda que promovían estas revistas.

\footnotetext{
${ }^{24}$ La realización de los cursos de extensión universitaria fue una iniciativa del entonces presidente del Círculo Médico Argentino y Centro de Estudiantes de Medicina (CMA-CEM), Osvaldo Loudet, cuyo proyecto fue aprobado dentro de la FUBA en 1915. Osvaldo Loudet, "Memoria del CMA- CEM. Periodo 1914-1915", Revista del CMA-CEM, año XV, nº 165- 166, Buenos Aires, 1915, 574- 576.

${ }^{25}$ Natalia Bustelo, "La juventud... op. cit..
} 


\section{"Niños bien", "pingüinos", "hombres de orden": prácticas y prototipos de alteridad de los estudiantes reformistas de izquierda}

Los cuestionamientos de las revistas que analizamos tienen como punto común y antecedente la labor del Ateneo Universitario ya que tanto el director de Themis, Gonzalo Muñoz Montoro, como el de La Cureta, José Belbey, fueron socios y partícipes de las actividades del Ateneo. Tal como ha señalado Biagini, esta agrupación estudiantil, que había aparecido en 1914 como la sección universitaria dentro del Ateneo Hispanoamericano del cual luego se independiza, se caracterizó por promover instancias de asociación con afanes culturales y por su enfrentamiento a los males de la universidad en tanto foco de camarilla y atraso cultural ${ }^{26}$. Asimismo, las críticas de los ateneístas se dirigieron también al estudiantado universitario. Para ello desde la revista Ideas y posteriormente desde el periódico Clarín $^{27}$ emprendieron una campaña en contra de los "niños bien" o "pingüinos" aludiendo a un estereotipo de mal estudiante de carácter frívolo, de moral licenciosa y de aspiraciones meramente profesionales.

Al iniciarse el movimiento de la Reforma, los jóvenes de Ideas continuaron sus críticas hacia el grueso del estudiantado acentuando nuevos aspectos distinguiendo al "niño bien" de los que ellos consideraban verdaderos estudiantes comprometidos con la renovación universitaria. De este modo, José María Moner Sans, uno de los principales animadores del Ateneo que ocupó la dirección de ambas publicaciones, señalaba la adhesión a dicho movimiento por parte de muchos jóvenes como una moda pasajera:

...en estas revoluciones recientes, la mayoría sólo quiere provocar el tumulto y el escándalo, para asegurarse así una "farra" más a la lista de sus famosos desordenes en "cabarets" y en otros lugares de pública diversión. Los "pingüinos" o "niños bien" que pasean por Florida, no encuentran al asunto más atractivos que el dar un nuevo pretexto al vandalismo de la respectiva "patota". Poco saben ellos de docencia libre, de sistema de seminario, de renovación periódica y completa de las autoridades, de representación equitativa de profesores suplentes y alumnos en los Consejos Directivos, etc ${ }^{28}$.

Esta cita recoge dos de los puntos sobre la vida estudiantil que fueron objeto de atención en las fuentes reformistas que analizamos. Por un lado, se señalan una serie de temas relativos a la renovación universitaria en los asuntos educativos que implicaban la participación estudiantil, a los cuales nos referiremos posteriormente, y por otro, aquellos

\footnotetext{
${ }^{26}$ Hugo Biagini, La contracultura juvenil. De la emancipación a los indignados, Buenos Aires, Capital Intelectual, 2012, 199.

${ }^{27}$ Ideas y Clarín fueron publicaciones del Ateneo pero, mientras que la primera se constituyó como un órgano cultural que recogía los documentos de esa asociación, Clarín se lanzó posteriormente como una publicación paralela con un perfil político diferente al de Ideas. Sin embargo, mantuvieron poco tiempo de coexistencia ya que, al poco tiempo de aparecer Clarín, Ideas dejó de editarse. Para un análisis de estas publicaciones y del grupo del Ateneo véase: Bustelo, Op. Cit., 85-99, 103- 106 y 227- 234.

${ }^{28}$ José María Monner Sans, “Todos somos reformistas”, Ideas, año IV, n 19-20, Buenos Aires, 1918, 69-70.
} 
que se dirigen a reformar los modos y comportamientos de los estudiantes que resultaban distracciones evasivas para el compromiso reformista.

En este último sentido, las críticas de estos escritos cumplían una doble función en la medida en que, por un lado, contribuían a definir una identidad dentro del reformismo al marcar una diferencia con otros grupos y prácticas estudiantiles que denunciaban ${ }^{29}$ y, por otro lado, cumplían una función pedagógica que aleccionaba a base de señalar los malos ejemplos en la vida estudiantil a fin de socializar nuevas conductas y actitudes dentro y fuera de la universidad. Asimismo, si bien estos textos coincidían en los males que señalaban, dichas interpelaciones estuvieron condicionadas según el género periodístico y el tipo de público al que se dirigían. En este sentido, se advierte una diferencia entre las revistas Themis y La Cureta, que respondían a un ambiente estrictamente estudiantil y las publicaciones del periodismo político estudiantil de tipo independiente, como Clarín y Bases que podían dirigirse de un modo más directo hacia sus lectores ${ }^{30}$. Estos últimos se caracterizaron también por abordar temas culturales, políticos y económicos a escala nacional e internacional que excedían los asuntos universitarios abordados por las demás revistas $^{31}$. Asimismo, Clarín se destacó por contar con colaboraciones de reconocidos políticos e intelectuales argentinos como Alfredo Palacios y José Ingenieros y los escritores Ricardo Rojas y Manuel Gálvez.

De este modo, las críticas de carácter más condenatorio procedieron de estas últimas revistas. Tal como se observa en el fragmento ya citado de Monner Sans se atacaban las formas comunes de ocio de los universitarios del periodo asociadas a los paseos por la calle Florida y los cabarets. Esta lista de recreaciones se completa añadiendo a los paseos por los

\footnotetext{
${ }^{29}$ Seguimos el planteamiento de Hall quien señala que, en contradicción directa con la forma como se las evoca constantemente, las identidades emergen del juego de modalidades específicas de poder y, por ello, son más el producto de la marcación de la diferencia y la exclusión que signo de una unidad idéntica y naturalmente constituida. Stuart Hall, "Introducción: ¿quién necesita una identidad?", Stuar Hall, y Paul Du Gay, Cuestiones de identidad cultural, Buenos Aires, Amorrortu, 2003, [1996], 13-39.

${ }^{30}$ Themis pertenecía al Centro de Estudiantes de Derecho (CED). Al igual que los demás centros estudiantiles, la revista del CED se caracterizaba por la reproducción de apuntes y artículos de especialistas en la materia. Si bien la dirección de Muñoz Montoro le otorgó una nueva impronta a la revista, que adopta el nombre de Themis y un nuevo formato, el proyecto del director de Themis continuó respondiendo a las formalidades institucionales del centro y a un público compuesto por sus asociados. La Cureta representaba un periodismo independiente dentro del ambiente estudiantil de medicina, en tanto que no dependía de la entidad estudiantil oficial representada en el Círculo Médico Argentino y Centro de Estudiantes de Medicina (CMA-CEM). En cambio, tal como ha estudiado Bustelo, Bases y Clarín se ubican dentro del primer periodismo político estudiantil y constituían proyectos de aspiraciones editoriales más amplias. Bases fue elaborada por jóvenes que, como Solari, buscaban que el PS adhiriera a la Internacional Comunista, iniciativa que tenía por referente al senador Enrique del Valle Iberlucea. Por su parte, Clarín era una publicación del Comité de Acción Social Ateneo Universitario que mantuvo una línea afín al Partido Socialista Internacional (PSI) creado en 1918 y que en 1920 cambió su nombre a Partido Comunista (Bustelo, Op. cit, 225-257).

${ }^{31}$ De este modo, la condición de izquierda de estos grupos, que hemos resaltado en la introducción, resulta más explícita en las agrupaciones asociadas a Bases a y a Clarín cuyos miembros se posicionan políticamente dentro una rama del socialismo. Sin embargo, tal como hemos señalado, la inclusión de las demás revistas estudiantiles dentro de esta trama se justifica al interior del movimiento estudiantil en la vinculación que pretenden establecer con el movimiento obrero en contraposición a otros grupos reformistas que apoyaron una postura nacionalista opuesta a esa reivindicación.
} 
parques de Palermo; las carreras de caballos en el hipódromo y las funciones de ópera en el Teatro Colón. Ese tipo de ocio estudiantil aparece claramente asociado a los lugares y las modas de recreación propios de la elite porteña ${ }^{32}$. En este sentido, gran parte de las prácticas de consumo y de recreación estudiantil, que son atacadas en las publicaciones que analizamos, respondían a las pautas culturales de esos sectores encumbrados que tradicionalmente estaban asociados con la universidad.

Por su parte, las revistas estudiantiles como La Cureta y Themis también cuestionaron distintos aspectos que caracterizaban la vida cotidiana de los universitarios, pero de un modo más conciliatorio que buscaba más la captación de adhesiones que la condena excluyente. En esas notas se observa un rechazo hacia la formalidad artificiosa que rodeaba a las comidas y banquetes como instancias de camaradería masculina. En contraposición a la usual realización de estos eventos (cuyos detalles eran registrados en la sección de noticias sociales de los grandes diarios y cuya ocasión permitía el lucimiento social tanto de los homenajeados como de los múltiples oradores que participaban) los jóvenes de La Cureta ubicaban "los discursos, con más o menos, pretensiones en los banquetes de egresados" entre las cosas que "Nos Aburren",33. Asimismo, en contra del empaque formal que caracterizaba los actos académicos, el director de Themis, Gonzalo Muñoz Montoro lamentaba que las colaciones de grados tuvieran lugar "en el más antipático ambiente de amanerada aristocracia" y llamaba a que la Facultad abriera "sus puertas al pueblo que con sus luchas diarias la sostiene y de ella espera el alivio de muchos dolores"34. Finalmente, estos comentarios cuestionaban los modos de sociabilidad estudiantil que, como ya mencionamos, caracterizaban a los encuentros estudiantiles de principios de siglo bajo ciertas formas protocolares y dentro de los lugares sociales de la élite. En un sentido contrario, así relataba en la revista Themis una recepción de una comitiva de estudiantes chilenos en 1918: "Sin repórteres ni fotógrafos de diarios y revistas, sin profesores de la Facultad ni miembros oficiales de la embajada, porque nada de ello exigíalo el ambiente de íntima y franca camaradería, se efectuó la sencilla fiesta." 35 .

Asimismo, en estas últimas revistas la crítica en algunos casos se manifestó en forma de ausencias desterrando a la reseña de los deportes como una instancia representativa de la vida universitaria. Con ello se diferenciaban de las revistas de los centros donde se intentaba fomentar el desarrollo de la cultura física exaltándola, en algunos casos, como una práctica diferenciadora y excluyente. Sin embargo, pese a la propaganda de los centros para instaurar el deporte como una instancia de sociabilidad, el poco éxito de las comisiones de deporte en conseguir adeptos para la realización de torneos revela que su implementación no fue mayoritaria. Por otra parte, si bien se dieron iniciativas de estas entidades de tramitar plazas públicas de ejercicio físicos ${ }^{36}$, la práctica del deporte era desarrollada en clubes y asociaciones externas a la universidad como el

\footnotetext{
${ }^{32}$ Losada, L. Op.. cit.

${ }^{33}$ Roberto Fernández Ríos, “Cosas que nos aburren”, La Cureta, año II, no 11, Buenos Aires, $1919,144$.

${ }^{34}$ Gonzalo Muñoz Montoro, "La colación de grados”, Themis, año XI, no 72, Buenos Aires, 1918, 5.

${ }^{35}$ S.n., Los estudiantes chilenos" Themis, año XI, n⿳ 7, Buenos Aires, 1918 111- 112.

${ }^{36}$ Federación Universitaria, "Sesión ordinaria 21/07/1916", Revista del CEI, año XVIII, n¹84, Buenos Aires, 1917, 93.
} 
Club de Gimnasia y Esgrima, El Law Tennis Club, el Buenos Aires Rowing Club, entre otros. Tanto esta falta de accesibilidad como el elitismo que caracterizaba a la implementación de ciertos deportes se hacían presentes en los irónicos comentarios de $L a$ Cureta en contra de la necesidad de solicitar un instructor de tiro:

Nuestra misión de estudiantes o de médicos está reñida con el tiro al blanco...o al negro, y para cazar liebres en el Sur o cacatúas en el Norte...-amenos pasatiempos... (...)

Más nos valiera poseer cómodos campos de deportes para completar nuestro desarrollo físico, y entonces sería el caso solicitar algo, no al Comando militar, sino a algunos potentados porteños que tanto abundan y tan poco lucen ${ }^{37}$.

De este modo, se criticaban los aspectos de militarización deportiva que suponían los concursos de tiro comúnmente alabados en las revistas de los centros. Según señala Roldán, el tiro al blanco, que inicialmente surge en la Argentina como una práctica deportiva difundida por los colonos suizos y por las elites locales, se rodeó a partir de 1917 de un ideario patriótico y militarizante difundido por el Tiro Nacional Argentino y por asociaciones de derecha nacionalista como la Liga Patriótica, que inicia por estos años una activa campaña, dirigida a la juventud, a favor de ésta práctica $^{38}$. En este sentido, el comentario de La Cureta discute con uno de los modelos de sociabilidad ligados a estas asociaciones que gozaban de difusión entre los universitarios y que, desde el ideario nacionalista del tiro, competían para encauzar las formas de ocio de la juventud.

Asimismo, en paralelo a los centros la difusión de los deportes fue el objeto de otra asociación estudiantil creada en 1918. En este sentido, la aparición del Club Universitario fue saludada por Themis y reseñada, no sin cierto distanciamiento, por La Cureta y Bases. Sin embargo, estos saludos iniciales no implican una solidaridad ideológica entre estos grupos, ni una identidad con la sociabilidad que proponía los estudiantes del Club la cual, como ha analizado Gerardo Fuentes, fomentaba un perfil estudiantil basado en la imagen de joven masculino, estudioso, deportivo y no conflictivo. De este modo, la creación del $C l u b$ revela la diversificación de las formas asociativas estudiantiles en el marco de la implementación de la Reforma y de ampliación de la matrícula universitaria. En relación al $C l u b$, este proceso se expresa mediante la creación de un espacio de interacción extra universitario con determinados valores (deporte amateur, camaradería, formación integral) en el que sostenía una línea de apoliticismo y se buscaba marcar la distinción y diferencia del grupo social que lo conformaba ${ }^{39}$.

Sin embargo, el afán crítico de las publicaciones que analizamos se mostraba menos consensuado en relación a otros aspectos de la vida estudiantil. En este sentido, los comentarios hacia las prácticas recreativas asociadas al día de los estudiantes permiten observar ciertas negociaciones y licencias a la hora de socializar nuevas conductas.

\footnotetext{
${ }^{37}$ S.n ,"Un instructor de tiro", La Cureta, año II, no 7, Buenos Aires, 1919, 21.

38 Diego P. Roldán, "El Tiro Suizo de Rosario. Prácticas, corporalidades, cultura física e identidades nacionales (Rosario, 1889- 1920), Actas de las XIV Jornadas Interescuelas y Departamentos de Historia, Universidad Nacional de Cuyo, Mendoza, del 2 al 5 de octubre de 2013, 13- 17.

${ }^{39}$ Sebastián- Gerardo Fuentes, "Un club... op.cit.
} 
Usualmente estas festividades daban objeto a críticas por las conductas estudiantiles, caracterizadas según los comentarios de las revistas de los centros por los excesos en el consumo de bebidas alcohólicas, la presencia de mujeres "de mala calaña" en la realización de la farándula y los bailes del internado realizados por los estudiantes practicantes de medicina. Estos festejos, que como señalamos eran una práctica común entre los estudiantes de la región, se llevaban a cabo mediante la realización colectiva de una farándula o desfile de carrozas por las principales avenidas de la ciudad y de otras actividades (bailes, funciones teatrales, banquetes) organizadas por los estudiantes de distintas carreras. Sin embargo, usualmente los cuestionamientos de los centros atacaban sólo a la exhibición de aquellos comportamientos que contravenían las normas del decoro público o que dañaban la imagen de estudiantes responsables que deseaban proyectar ante las autoridades universitarias.

Cuando se inicia el movimiento reformista, se registran reformulaciones de estas festividades que comienzan a incluir significados de dicho movimiento. En ese sentido, se citan las fiestas de los estudiantes cordobeses quienes festejaron la llegada de la primavera con la realización de un acto titulado "Entierro del viejo régimen universitario" 40 . Por el contrario, entre los reformistas porteños no encontramos este tipo de prácticas diferenciadas de los usuales festejos. Sin embargo, los comentarios hacia la festividad estudiantil adquirieron un cariz distinto al que tenía en las revistas de los centros. Tanto en Clarín como en Bases, si bien no se citan referencias específicas sobre las fiestas del día del estudiante, la censura hacia lo que se consideraba como distracciones de vida licenciosa de los jóvenes en los cabarets y demás ámbitos de recreación nocturna fue unánime y generalizada.

Por el contrario, Themis y La Cureta no formularon este énfasis marcadamente condenatorio, aunque sí se observa un intento de encauzar este tipo de prácticas. En ese sentido, Gonzalo Muñoz Montoro se expresaba, antes de asumir la dirección de Themis, en contra de la implícita aceptación de la presencia de prostitutas en los festejos estudiantiles. Asimismo, enmarcaba esta crítica, no ya desde la común apelación al decoro externo, sino desde la denuncia de los problemas de índole social que traían aparejadas esas conductas. Así, se lee en su reseña de un folleto en contra de "la trata de blancas": "La lectura del folleto sería muy interesante en esta casa de gente joven "que se deja vivir", y donde por la imposición colectiva tenemos que festejar nuestro día con un baile- ya sabemos de qué índole-" $"$. Sin embargo, en Themis convivieron voces que defendían la realización de estas fiestas como representaciones del espíritu universitario junto a otras que eran contrarias a los excesos y la falta de cultura de estas manifestaciones.

\footnotetext{
${ }^{40}$ Sin embargo, estos festejos reformistas no remplazaron completamente las tradicionales fiestas de los estudiantes cordobeses. Los tres festejos realizados en el ámbito cordobés contribuyen a ilustrar los pasos fronterizos que, tal como señala Bisso, pueden encontrarse entre la sociabilidad, la militancia y la simpatía ideológica. Así, en paralelo al acto "entierro del régimen universitario", se realizaron por separado la tradicional farándula del día 21 y la procesión católica de la virgen de La Merced. "Conflicto universitario de Córdoba", La Prensa, Buenos Aires, 30/09/1918, 9.

${ }^{41}$ Gonzalo Muñoz Montoro, [Reseña de] Bott, Ernesto "Las condiciones contra la lucha de la trata de blancas", Revista del Centro de Estudiantes de Derecho, año XI, nº 66, Buenos Aires, 1917, 630.
} 
Por su parte en la revista La Cureta se intentaba presentar estas prácticas recreativas como un "paréntesis de liberalidad y expansión"42, o se alentaba a que adquiriesen un carácter más refinado respondiendo a las críticas ${ }^{43}$ de las que eran objeto las fiestas de los estudiantes de medicina ${ }^{44}$. De este modo, la festividad y la alegría estudiantil no aparecían reñidas con la seriedad y el compromiso que proponía la revista al apelar, en ese mismo número, a seguir el ejemplo de la juventud cordobesa que: "se estrecha en fraternal abrazo con el proletariado, se une a él convencida que su alma forma parte integrante del pueblo que sufre y que trabaja y rompiendo con los convencionalismos anticuados, con las tradiciones ridículas no vacila un solo instante en marchar en pos de la bandera roja..." Así esta función modélica que difundía La Cureta contemplaba también a las diversiones en el día de la primavera, siempre y cuando no se olvidaran de los ideales que defendían:

En un día así no se puede menos que estar contento y que ser optimista. (...) Risas. ¡Brisas que acarician... Juventud! (...) La muchachada ha salido a la calle. Ha bailado y cantado en nuestros escenarios. (...)

Porque estamos seguros de que esa muchachada que hoy ríe, juega, canta y ama, será la que mañana en cualquier sitio (...) se levante de una vez (...) y haga lo que debe hacer en pro de los ideales universitarios, que deben ser los de la Nación, y los del pueblo todo ${ }^{46}$.

Estas citas encontradas entre la condena y la aprobación de la festividad estudiantil se asimilan a las tensiones que Bisso ha estudiado en la prensa socialista de los años 30, entre las diferentes acepciones de la sociabilidad provenientes de la herencia iluminista. Estas tensiones, presentes también en la tradición liberal argentina que difundió esas nociones de la Ilustración, discutían sobre los márgenes de libertad y de distracción que debían o no permitirse en la difusión de la sociabilidad acorde con el sentido programático que tenía ese concepto en la época ${ }^{47}$.

Sin embargo, pese esta permisividad La Cureta también criticó pedagógicamente los rasgos del prototipo de estudiante que debía evitarse. Entre las notas que lo señalaban figuraba su extrema preocupación por las modas y el bien vestir ("preocupa más una mancha en los botines que en la conciencia"); su pasividad para soportar las injusticias y a

\footnotetext{
${ }^{42}$ S.n "El baile del Internado", La Cureta, año I, no 5, Buenos Aires, 1918, 119.

${ }^{43}$ En especial las fiestas del internado, realizadas por los estudiantes practicantes de medicina, eran objeto de severas críticas en publicaciones como Ideas y en la Revista del CEI al punto que se las caracterizaba como "orgías". Asimismo, dichas fiestas escandalizaban la moral de la época por las bromas morbosas que los practicantes llevaban a cabo asustando a las mujeres que asistían con disfraces realizados a bases de sábanas y piezas humanas. Francisco Canaro, "Los Bailes del Internado", Francisco Canaro, Mis Memorias. Mis bodas de oro con el tango, Buenos Aires, Corregidor, 1999, 71-72.

44"Baile del Internado", La Cureta, año II, n 11, Buenos Aires, 1919, 134.

${ }^{45}$ Hernán Vargas, "Ejemplo de la juventud Cordobesa”, La Cureta, año I, no 5, Buenos Aires, $1918,117$.

${ }^{46}$ S.n, "Reflexiones en torno al Día de los estudiantes", La Cureta, año I, no 5, 1918, 97.

${ }^{47}$ Entre las tensiones presentes en la matriz ilustrada del concepto de sociabilidad, Bisso rescata las acepciones encontradas de autores como Rousseau y Jovellanos. Así mientras que el primero de estos autores fomentaba el desarrollo de la sociabilidad mediante la realización de festejos públicos para desarrollar el patriotismo y el civismo, pero censuraba las distracciones populares que no confluían a ese fin; el segundo no apoyaba este tipo de censuras a los entrenamientos populares. Bisso, Op. cit, 13-30.
} 
los malos profesores en la universidad ("nunca una inquietud jamás una protesta"); su desconocimiento de la política universitaria en las elecciones de los centros estudiantiles ("se entera por La Prensa (lee La Prensa) que su candidato ganó. Sonríe (...) ya podrá decir: yo sostuve a fulano,") y su oposición a todo cambio en los movimientos estudiantiles (excepto "Cuando ve que el movimiento está apoyado por el Gobierno. Cuando toda la mayoría se ha plegado, y se han solidarizado todas las federaciones, entonces, sí. Él también se contagia y.. Hicimos la Reforma... $)^{48}$.

En esta cita, el tema de la moda, punto común en las publicaciones que analizamos, se señala como el reflejo externo de una condición moral. Ese mismo recurso era utilizado por Bases en donde el tema de la moda era comúnmente señalado como indicador de pertenencia o de alteridad para interpelar al público universitario:

Ir a la moda es la exclusiva preocupación de una gran parte de los jóvenes de aquí. (...) Y así se da un espectáculo cuasi carnavalesco (...), de pobrecitos jovencitos sin sexo y sin seso que llevan cabalgando sobre sus narices sendas anteojeras de carey barato; con patillas- marcas que voluntariamente se ha dado la majada;- con trajes ceñidos al cuerpo como para que no se escape- difícil será- la imbecilidad que lleva metida bien adentro... (...)

Miopes de ocasión, próceres de papel pintado, parisienses de a tres por diez... aprendices de invertidos, paloteros, patrioteros, megaterios. Señoritos.

(...) ¿Dónde hay aquí un hombre, dónde? No son de los nuestros. (...) llevemos con orgullo nuestro desaliño bohemio, vivamos más heroica, más intensamente nuestra bohemia misma, que es fiebre azul de lo bello, creciente anhelo de superación, altivez indomable, acción batalladora, entusiasmo, amor, juventud! $!^{9}$.

Esta extensa cita, de la cual hemos extraído un fragmento que da título a este trabajo, permite visualizar de modo general el prototipo de alteridad de los reformistas de izquierda mediante una crítica antiburguesa contra el universitario frívolo, pendiente a las modas y que, como hijo procedente de familias de elites, participaba de la costumbre de realizar el grand tour europeo, viaje que tenía a París por destino preferencial ${ }^{50}$. De este modo, la denuncia hacia la preocupación extrema a la moda no sólo se explica por la crítica hacia la falta de inquietudes culturales y de compromiso, que ya hemos señalado en anteriores críticas, sino que también puede aludir a las dificultades materiales de aquellos jóvenes "bohemios" o de los "estudiantes pobres" que aparecen representados en estas revistas, como verdaderos ejemplos de esfuerzo y mérito. De este modo, las críticas analizadas en este apartado ofrecen interesantes indicios de la trama cotidiana de los conflictos generados por el ingreso de los sectores medios a la educación superior y de las disputas de estos actores por ocupar un lugar dentro de la universidad.

\footnotetext{
${ }^{48}$ José Belbey, “Los remansos. (Ensayos sin pretensiones)”, La Cureta, año II, nº 9, Buenos Aires, 1919, 6669.

49 S.n., "La moda", Bases, año I, no 1, Buenos Aires, 1919, 2.

${ }^{50}$ Leandro Losada, Op. cit. 151- 166.
} 
Al mismo tiempo la cita de Bases, se destaca por reivindicar, como propio de los jóvenes reformistas de izquierda, el modelo de sociabilidad bohemia difundido desde principios de siglo entre los círculos intelectuales porteños, por obra de Rubén Darío, que aparece aludido en la frase de "fiebre azul de lo bello" 51 . Sin embargo, lejos de apelar a mala vida y a los excesos nocturnos asociados a la bohemia, el comentario de Bases expresa un juvenilismo que, con sus notas de "altivez" y "acción batalladora" se combina con una sensibilidad vitalista propia de algunos grupos reformistas durante la posguerra ${ }^{52}$.

Por otra parte, el tema de la moda era frecuentemente asociado al de la virilidad como temas para interpelar a los lectores de estas revistas, las cuales se dirigían exclusivamente al universo masculino de los estudiantes que representaban al grueso de la población universitaria. Tal como ha analizado Milanesio, la masculinidad constituyó uno de los elementos distintivos en los discursos reformistas en tanto que en ellos se apelaba a la virilidad para identificar una serie de atributos propios de la juventud de ese movimiento $^{53}$. Así, en Clarín o Bases figuran varias alusiones en las que aparece la relación hombría- denuncia, ya sea, como vimos, para señalar a los "jovencitos sin sexo" que vestían a la moda o para identificarse, los redactores de Clarín, como: "hombres jóvenes a quienes la Universidad no ha logrado castrar" ${ }^{\prime 54}$. Asimismo, en Themis lo viril era sinónimo de valentía y lo apuesto a lo conservador tal como se observa en la calificación de las posturas de los estudiantes en cuanto a la impugnación de un profesor: "Como alguien dijera, extremando sin duda la expresión, hay dos tendencias en la Asamblea, la de los hombres y la de las mujeres"

Esta falta de referencias a las mujeres puede explicarse en parte por la minoritaria presencia femenina en la educación superior y porque las concepciones patriarcales en relación al papel y la función maternal que la mujer debía ocupar en la sociedad eran una nota característica de la de la época aun dentro de los círculos intelectuales considerados progresistas $^{56}$. Sin embargo, pese a esta tendencia general, y a que los reformistas en general no incluyeron dentro de sus reivindicaciones el derecho a la educación superior para la mujer, en las revistas que analizamos la presencia de escritoras y de artículos que abogaban por la emancipación de la mujer, marcaba un punto de diferencia con las demás publicaciones estudiantiles.

\footnotetext{
${ }^{51}$ Pablo Ansolabehere, "La vida bohemia en Buenos Aires (1880-1920): lugares, itinerarios y personajes" Paula Bruno (dir.) Sociabilidades y vida cultural. Buenos Aires, 1860-1930, Buenos Aires, UNQ, 2014, 155165.

${ }^{52}$ María Pía López, Hacia una vida intensa: una historia de la sensibilidad vitalista, Buenos Aires, Eudeba, 2010.

${ }^{53}$ Según esta autora los reformistas si revindicaron este derecho de educación para los obreros, pero no para las mujeres. Sin embargo, en dicho estudio se equipara el reclamo por la educación para la clase obrera con la propuesta de extensión universitaria señalada por Loudet; omitiendo con ello las diferencias entre ambas reivindicaciones. Natalia Milanesio, "Gender and Generation: The University Reform Movement in Argentina, 1918”, Journal of Social History, vol 39, n² 2, 2005, 505-529.

${ }^{54}$ S.n., Clarín, año I, no 3, Buenos Aires, 1919.

${ }^{55}$ Raúl C. Migone, "El caso del Dr. Osvaldo Piñero", Themis, año XI, no 71, 1918, 159.

${ }^{56}$ Dora Barrancos, Mujeres en la Sociedad Argentina. Una historia de cinco siglos, Buenos Aires, Sudamericana, 2010.
} 
En este sentido, debe resaltarse la participación de la periodista Lola Pita en Themis defendiendo la participación de la mujer en la profesión de la abogacía ${ }^{57}$. Si bien esta propuesta se basaba en una necesidad hipotética de contar con representantes femeninas para defender a las mujeres en el marco de la posible implantación del divorcio vincular, su planteamiento resulta significativo dentro de la Facultad de Derecho la cual, dado el perfil ocupacional de sus egresados orientado a formar a las clases dirigentes, resultaba menos abierta al ingreso de las mujeres.

Asimismo, en Clarín y Bases fueron comunes las posiciones favorables a la mujer. Dicho posicionamiento puede explicarse en parte dado que ambas publicaciones estaban alineadas con ramas del socialismo, partido que se caracterizó por elevar las reivindicaciones de la mujer por vía legislativa ${ }^{58}$. Por otra parte, en estas revistas las mujeres, al igual que los jóvenes, también fueron objeto de crítica por su frivolidad, aunque se aducían estos males como una consecuencia de un régimen de opresión que esclavizaba a la mujer:

La educación familiar, la complicidad de la sacristía, la unánime complacencia del sexo opuesto, son los primeros términos que aparecen conspirando contra de la joven. $\mathrm{Y}$ sin embargo, no son más que asteroides que gravitan en torno a la estrella central: la carencia de libertad económica. Toda nuestra cacareada civilización, ¿qué ha hecho en pro de la elevación social de la mujer? Nada ${ }^{59}$.

De este modo, si bien la reivindicación del derecho de las mujeres a la educación superior no ocupó un lugar predominante dentro de la agenda de reclamos de estas revistas, las posturas registradas revelan un posicionamiento diferenciado que hacía a estos jóvenes proclives a manifestarse en contra de distintas injusticias (tutela masculina, falta de educación, exclusión de la vida pública) que la sociedad de la época naturalizaba dentro de concepciones predominantes sobre el papel de la mujer.

Asimismo, más allá de la diferenciación social que se exhibía por medio de la vestimenta y de las alusiones a la masculinidad, el recurso de apelar a la distinción entre moralidad y moda figuró, al igual que la práctica del tiro, como indicador de alteridad con el cual los reformistas de izquierdas se diferenciaron de los jóvenes nacionalistas "paloteros" que adhirieron a la Liga Patriótica, a la cual ya hemos aludido. Tal como se denunciaba en Themis a raíz de los episodios ocurridos durante las protestas obreras de principios de 1919, en donde varios universitarios participaron en la represión de los manifestantes, así como en la quema de locales y centros culturales obreros: "Centenares de jovenzuelos, para mayor vergüenza trajeados a la moda, y universitarios muchos de ellos, para mayor escarnio, cometieron (...) toda clase de atentados a las más elementales libertades consagradas por la constitución"60.

\footnotetext{
${ }^{57}$ Lola Pita, "La Mujer como abogado", Themis, año XI, nº 69, Buenos Aires, 1918,119-121.

${ }^{58}$ Osvaldo Graciano, "El Partido Socialista de Argentina: su trayectoria histórica y sus desafíos políticos en las primeras décadas del siglo XX", A Contra Corriente. Una revista de historia social y literatura de América Latina, vol. 7, nº3, Raleigh, 2010, 23.

${ }^{59}$ Eugenio Gallina Rolli, “A la caza de marido”, Clarín, año I, no 11, Buenos Aires, 1920.

${ }^{60}$ Fray Quimeras, "Pequeñas y grandes cosas. Un cartel”, Themis, año, XI, nº 73, Buenos Aires, 1919, 193.
} 
Como otros acontecimientos de radicalización política, los sucesos de la "Semana Trágica", nombre con el cual la historiografía denominó a esos episodios, cristalizaron las diferencias políticas entre los estudiantes reformistas y los nacionalistas que se adhieren a la Liga Patriótica y a otras agrupaciones del reformismo universitario ${ }^{61}$. Así, de la crítica del estudiante licencioso y despreocupado se pasó a la crítica del estudiante reaccionario y la figura del "niño bien" se identificó entonces a la del "hombre de orden" criticado frecuente en el semanario Bases.

De este modo, estas críticas revelan que tanto las prácticas recreativas (los mencionados excesos en la vida nocturna) como las cotidianas (un paseo por la calle Florida o por Palermo, el uso de determinado atuendo o la lectura de cierto periódico) se señalaban como indicadores que no cuadraban con el perfil estudiantil que los reformistas deseaban sociabilizar, caracterizado no sólo por su compromiso en la renovación universitaria sino también por la denuncia de las injusticias que sufrían los sectores sociales menos favorecidos adhiriendo con ello a un movimiento de emancipación de la Humanidad. Para ello, tal como ha estudiado Graciano, además de la militancia en el reformismo, los actores identificados con la izquierda de dicho movimiento legitimaron su acción pública en su condición de intelectuales a través de la denuncia de las injusticias de un orden establecido ${ }^{62}$ y apelaron, como hemos visto, a un fundamento moral para sustentar sus críticas. Asimismo, tal como estudiaremos en el apartado siguiente, buscaron afirmarse a través de una serie de propuestas tendientes a la renovación pedagógica y por medio de una reformulación del carácter y de las funciones de las asociaciones gremiales estudiantiles.

\section{Hacia la renovación universitaria}

En consonancia con el llamado citado de Ideas, que apuntaba a la necesidad de un compromiso de los estudiantes en la renovación universitaria, el periódico Clarín publicaba un manifiesto del Ateneo en el que se delegaba a los estudiantes la responsabilidad de involucrarse y defender la implementación de la Reforma. En ese texto aseguraban que: "Si el gobierno y la organización de la enseñanza fue, hasta hace poco, materia exclusiva de la Universidad y de algunos políticos, el decreto del 11 de septiembre del año ppdo. la ha tornado en función estudiantil. (...) A nadie escapa la trascendencia de la función y la precaria capacidad actual de la masa estudiantil para ejercerla"63.

Apelando a esta necesidad, los ateneístas instituían una "Junta de Estudios" cuya primera tarea fue una encuesta entre los estudiantes de diferentes Facultades sobre distintos puntos de la Reforma (condiciones de ingreso, organización de la docencia, formas de enseñanza, entre otras). Al mismo tiempo, programaron un ciclo de conferencias sobre aspectos de la educación universitaria que contó entre sus primeros disertantes al pedagogo

\footnotetext{
${ }^{61}$ Entre estas se señalan el partido Unión Universitaria y la Revista Nacional pertenecientes a estudiantes de la Facultad de Derecho y el Colegio Novecentista que mantienen por esos años una postura nacionalista de resonancias católicas.

${ }^{62}$ Osvaldo Graciano, Op. cit., 50- 51.

${ }^{63}$ S.n., "Manifiesto del Ateneo Universitario. La Reforma Universitaria", Clarín, año I, no 6, Buenos Aires, 1918.
} 
Ernesto Nelson y que preveía la presencia de Alfredo Colmo, Juan B. Justo, Ricardo Rojas y de otros intelectuales. Sin embargo, esta renovación se expresó en otros ámbitos de la vida estudiantil y no estuvo exenta de ambigüedades. Tal como veremos en este apartado, las propuestas y las críticas en materia educativa aspiraron a reformar las conductas del alumnado y a democratizar los modos de promoción dentro de la universidad y los cuerpos gremiales estudiantiles, pero, en otros casos, sostuvieron posturas restrictivas en relación al ingreso a la universidad.

Tal como ha señalado Buchbinder, en su análisis de la participación y de la incidencia de los estudiantes en la vida universitaria tras la Reforma, los reclamos de los estudiantes fueron moderados y restringidos a temas académicos (sistemas de clasificación, irregularidades y arbitrariedades de profesores) vinculados a aquellas trabas o mecanismos que retrasaban la carrera e impedían el acceso al título profesional ${ }^{64}$. Asimismo, junto con estas demandas, en las revistas que analizamos se cuestionaron también algunos de los reclamos estudiantiles frente a las autoridades.

En este último aspecto, dentro de los reclamos más controvertidos puede citarse el de la implantación del examen de ingreso en Medicina. Esta medida, formulada con anterioridad por las distintas comisiones del CMA-CEM, se justificaba como una defensa de la calidad de la enseñanza dada la escasa preparación que recibían los ingresantes en la escuela secundaria. La restricción del ingreso fue defendida en La Cureta aunque señalando que su reglamentación debía plantearse junto con la reforma de contenidos del plan de estudios $^{65}$. Sin embargo, esta modificación en las condiciones de ingreso no contó con el apoyo unánime dentro del ambiente universitario y se señala como un punto de disidencia entre los grupos del movimiento reformista. Así, fue rechazado por la revista Bases, por la Revista del Centro de Estudiantes de Ingeniería y por una activa campaña de padres y estudiantes secundarios que organizaron una "junta pro derogación del examen de ingreso" "66 . Asimismo, la disputa por el ingreso señaló diferencias entre las federaciones estudiantiles del país, en tanto que la Federación Universitaria de Córdoba (FUC) y la Federación de Estudiantes del Litoral se manifestaron en contra de esta medida ante la Federación Universitaria Argentina (FUA) y fue un motivo de distanciamiento entre esta última organización y la FUBA que defendió la postura del $\mathrm{CEM}^{67}$. Finalmente, la imposición de esa medida fue la causante de la renuncia del Dr. Julio Méndez, primer Decano que asumió la conducción de la Facultad gracias al apoyo del voto estudiantil.

Al mismo tiempo, las críticas referentes a los temas universitarios abarcaron cuestiones que excedían los asuntos académicos en la medida en que también se dirigieron a las conductas de los alumnos que eran protagonistas de esas demandas. En La Cureta la

\footnotetext{
${ }^{64}$ Pablo Buchbinder, ¿Revolución en los claustros? La Reforma universitaria de 1918, Editorial Sudamericana, Buenos Aires, 2008, 149- 150.

${ }^{65}$ J. Puente, "El ingreso a la Facultad", La Cureta, año I, nº1, Buenos Aires, 1918, 15-16.

${ }^{66}$ Estos grupos expusieron distintos motivos para sustentar su oposición: "El examen de ingreso", Bases, año I, $\mathrm{n}^{\circ}$ 1, Buenos Aires, 1919; "El examen de ingreso debe derogarse", Revista del CEI, año XIX, n 202, Buenos Aires, 1919, 274- 280; "Creación de la Junta pro derogación del examen de ingreso", Archivo Histórico de la Universidad de Buenos Aires (AHUBA), caja R- 204.

${ }^{67}$ Raimundo Bosh, "Nuestras asociaciones estudiantiles", Revista del CMA-CEM, año XIX, n 212, Buenos Aires, 1919, 375- 385.
} 
renovación universitaria se expresó mediante una prédica democratizadora que criticaba tanto a los privilegios y los favoritismos que ejercían los profesores como a aquellos estudiantes que aceptaban estas conductas. Tal como se señalaba en una crítica hacia los ayudantes de cátedra que reproducían las jerarquías en el trato personal dentro del aula: "Pero compañeros! Precisamente cuando estamos bregando por la democratización de la enseñanza- cuando todos repudiamos la pose, el estiramiento, el Olimpismo de los profesores- resulta que tenemos entre nosotros el germen del mal"68. Al mismo tiempo, fueron comunes las denuncias en contra de los estudiantes que recurrían a la adulación, al uso de influencias personales y al dinero como medios de ascenso dentro de la universidad, así como otros procedimientos poco lícitos en la elección de los profesores suplentes y ayudantes de cátedra.

Desde otro aspecto, la apelación a implantar nuevas conductas y nuevos modos de actuar dentro de la universidad también se explican por la necesidad de lograr la acción colectiva para conseguir la renovación de la enseñanza. Este punto actuaba como un factor decisivo en las distintas recusaciones en contra de ciertos profesores a los que acusaban de un deficiente desempeño en el manejo de la cátedra, las cuales ganan difusión en la vida universitaria tras la Reforma. Sin embargo, el consenso estudiantil no siempre se lograba en dichos reclamos, especialmente en ambientes como el de la Facultad de Derecho el cual fue el más adverso a la implementación de la Reforma. En este sentido, los intereses personales, la apatía o el conservadurismo de los estudiantes fueron denunciados en Themis como causas del fracaso de la campaña contra el Dr. Osvaldo Piñero, titular de la cátedra de Derecho Penal $^{69}$. Otro ejemplo de las limitaciones estudiantiles para renovar la casa de estudios de derecho lo constituye el Affaire Dellepiane: un frustrado movimiento emprendido contra el profesor de Filosofía del Derecho, Antonio Dellepiane por los alumnos de quinto año. Los acontecimientos que acompañaron el caso, que adquirió resonancia pública dado el prestigio del profesor en cuestión, sirvieron para poner en evidencia las disidencias internas de los estudiantes de derecho a la hora de implementar el movimiento iniciado en Córdoba. Tal como relataba uno de los participantes desde la revista Ideas sobre este episodio que surgía tras la "heroica lección dada por la juventud cordobesa y su revolución histórica":

...este doloroso suceso, que debiendo ser la chispa de donde surgiera el más puro e idealista de los movimientos estudiantiles, quedó reducido a un despreciable motín de dudosa índole. (...) dio ocasión a notas obsecuentes, actitudes serviles y delaciones increíbles, produciendo la consiguiente dolorosa desilusión en el que descubría espíritus arteros y tortuosos donde había creído hallar almas rectas y puras ${ }^{70}$.

En medicina, pese a que las campañas críticas lograron mayores éxitos, los escritores de La Cureta continuaron con las denuncias contra la connivencia del alumnado

\footnotetext{
${ }^{68}$ S.n., "Por el laboratorio de histología", La Cureta, Año I, no 4, Buenos Aires, 1919, 72.

${ }^{69}$ Raúl Migone, Op. cit., 160.

${ }^{70}$ Horacio Pozzo, “El triste 'caso' del Dr. Dellepiane”, Ideas, año IV, n’ 19- 20, Buenos Aires, $1918,75$.
} 
y los malos profesores. Estas críticas se emparentan con las dirigidas a la "politiquería" de la universidad, señalada como un mal común en la vida de los centros de estudiantes. Especialmente en la Facultad de Derecho, la adhesión a ciertas camarillas o "patotas" identificadas a un bando de la política nacional actuaba como una carta de influencia no sólo en los centros estudiantiles sino en la relación con profesores y autoridades. Asimismo, estas prácticas formaban parte de la experiencia política para una gran parte del alumnado de esa Facultad conformado por los hijos de las elites dirigentes que acudían a la universidad como una antesala para su inserción en los puestos de gobierno.

La denuncia de estos temas revela la apreciación diferenciada que estos jóvenes de clase media hacían sobre la formación y los títulos universitarios al entenderlos no como un capital social para confirmar la pertenencia a una elite dirigente sino como una plataforma de inserción y ascenso social y profesional ${ }^{71}$. Dentro de este contexto, también puede interpretarse la "campaña de democratización" que tanto Themis como La Cureta alentaron dentro de los centros estudiantiles. Así, la comisión directiva del CED, que acompañó el equipo editorial de Themis, fue la primera en aplicar el voto secreto en las elecciones de dicho centro, a fin de favorecer "una mayor corrección y menos apasionamiento en la contienda"72. Por su parte, La Cureta proponía que la representación estudiantil en los consejos directivos se efectúe mediante elecciones realizadas en los centros.

Paralelamente, se defendía la función cultural y social de los centros en la realización de la extensión universitaria y la obtención de descuentos y beneficios para los estudiantes de menores recursos. Esa función educativa y mutualista de los centros figuraba también en Bases en donde Solari declaraba que "los centros deben formar entre los estudiantes una conciencia y una voluntad firme y decidida, prontas a salir en defensa de las causas justas y nobles y nunca dispuestas a proteger los propósitos de oportunistas y fariseos, que siempre solicitan su apoyo seguros del gran aporte que significa la adhesión juvenil",73.

De este modo, la renovación universitaria que promovían estas revistas se expresó además mediante una propuesta de reformulación de las labores de los centros estudiantiles. En este sentido, la prédica de La Cureta tuvo una expresión institucional en el CEM durante 1920-1921 cuando la comisión directiva de este centro estuvo presida por José Belbey. Al terminar su presidencia resumía los propósitos de "sociabilidad" ya señalados en la revista:

Son las instituciones estudiantiles las que deben reformarse hacia una comprensión más humana de la vida. Debe terminar de una vez por todas, la edad del estudiante informal, zumbón, arbitrario, insociable (...) debe poner toda su fe al servicio de una causa justa, noble y sana, aunque no golpee la puerta de nuestra universidad ${ }^{74}$.

\footnotetext{
${ }^{71}$ Osvaldo Graciano, Op. cit., 42.

${ }^{72}$ Eduardo Bullrich, "Memoria del Centro de la presidencia Bullrich", Themis, año XI, no 70, Buenos Aires, 1918, 173.

${ }^{73}$ Juan Antonio Solari, “La acción de los centros”, Bases, año I, nº 1, Buenos Aires, 1918, 1.

${ }^{74} J$ osé Belbey, "Palabras de un Compañero", La Cureta, año III, no 14, Buenos Aires, 1921, 250.
} 
Entre las iniciativas que dan cuenta de esta renovación del gremialismo con aspiraciones sociales y culturales, bajo la dirección de Belbey se hizo efectiva la propuesta del Ateneo del CMA-CEM que había sido acordada años atrás con el fin de "estimular los estudios literarios o de interés general que traspasen los dominios de las especializaciones

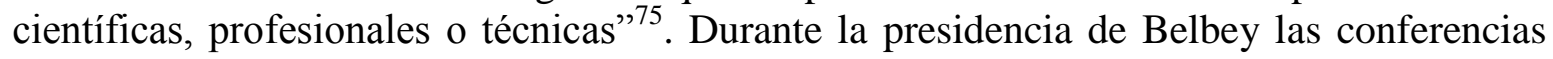
del Ateneo llegaron a publicarse regularmente editando los trabajos de Leopoldo Lugones, José Ingenieros, Clemente Onelli y Ernesto Nelson.

Asimismo, en una de estas entregas se reprodujo el "Mensaje de Henri Barbusse y Anatole France dirigido a los intelectuales y estudiantes de América Latina" ${ }^{\text {"76 }}$. De este modo, la difusión de este manifiesto, que invitaba a los intelectuales y estudiantes a sumarse a la "revolución de los espíritus" emprendida por el grupo Clarté en Francia, alentaba desde una iniciativa del centro de estudiantes a asumir un posicionamiento de izquierda. Este hecho, que se contraponía a la normativa de apoliticismo pautada en los estatutos del centro, revela una tendencia de diferenciación política e ideológica dentro de grupos partidarios en esas asociaciones. En este sentido, si bien la existencia de facciones o bandos estudiantiles de distintas orientaciones ideológicas y políticas constituía un rasgo presente desde principios de siglo, puede advertirse que, a partir de la radicalización que supuso el movimiento reformista en el clima ideológico de la posguerra y la revolución rusa, estos posicionamientos cobraron más relevancia en la vida universitaria.

Sin embargo, las propuestas de reformulación del gremialismo a la que apostaban estas revistas dependía del triunfo electoral en los comicios de los centros para llevarse a cabo. Así en 1921, en La Cureta se denunciaban las prácticas poco democráticas (sesiones secretas y diversas resoluciones sin aprobación de la asamblea) de la comisión directiva del CEM que sucedió a la integrada por Belbey: "el Ateneo no hace nada; la Extensión Universitaria no se realiza; las ediciones mínimas no se publican; no se dan las veladas artísticas de antes; la actuación en la Fed. Universitaria de Buenos Aires es deplorable y los problemas netamente estudiantiles se prostituyen con los egoísmos de la facción y del partido..."77. Pese a ello, posteriormente el grupo editorial de La Cureta volvió a triunfar electoralmente dentro del CEM retomando las propuestas que caracterizaron a la dirección de Belbey al frente de esa asociación.

Por su parte, las iniciativas de Themis no fueron retomadas por la comisión directiva del CED en donde desde 1919 hasta 1925 triunfó el partido de la Unión Universitaria el cual sostenía una interpretación nacionalista y antiliberal del movimiento de la Reforma. Sin embargo, la propuesta de Themis continuó en la facción estudiantil contraria que, desde 1919, se organizó en el Partido Blanco (en donde participaron los directores de Themis y de Clarín) y desde 1923 en el Partido Unión Reformista, el cual logra el triunfo de sus candidatos Florentino Sanguinetti, Julio V. González y Carlos Sánchez Viamonte, como consejeros estudiantiles dentro de Consejo Directivo de esa Facultad. De este modo, estas idas y contramarchas en las iniciativas reformistas revelan las tensiones y las diferencias

\footnotetext{
75“'Asamblea general ordinaria del 19/05/1917”, Revista del CMA- CEM, Año XVII, No 191, Buenos Aires, $1917,816$.

${ }^{76}$ Publicaciones del Ateneo del CMA y CEM, no 5, Buenos Aires, 1921.

${ }^{77}$ S.n., "El desbarajuste en el centro", La Cureta, año III, no 15, Buenos Aires, 1921, 21.
} 
ideológicas que se operaban dentro del movimiento estudiantil a la hora se seguir "el ejemplo de la juventud de Córdoba". Sin embargo, pese a esas tensiones, la continuidad de las iniciativas y prácticas que hemos estudiado en este apartado en relación a la renovación educativa y cultural de la universidad revela el alcance de estas propuestas de los reformistas de izquierda que persisten en las citadas agrupaciones a lo largo de la década del veinte.

\section{Consideraciones finales}

El recorrido aquí trazado muestra un intento por parte de algunas fracciones del reformismo por socializar ciertas conductas y prácticas de la vida estudiantil que contrastaban con los modos y formas sociales dominantes entre los universitarios del periodo. Si bien muchas de estas críticas ya figuraban en los centros de estudiantes o coincidía en algunos puntos con la moral de la época (que también condenaba por ejemplo los excesos en materia de sexualidad y de "vicios"), estos cuestionamientos se sustentaban en una fundamentación distinta.

Tal como observamos, el sentido de este amplio registro de críticas fue múltiple: apuntaban a condenar "vicios" considerados evasivos para promover nuevas conductas en la juventud; confrontaban con otros grupos estudiantiles que proponían otra inscripción ideológica para guiar el movimiento estudiantil; expresaban los intereses de nuevos grupos estudiantiles recién llegados a la universidad y las tensiones por ocupar un lugar dentro de ese ámbito y denunciaban las injusticias en las que se basaban los modos y conductas sociales que deseaban modificar. De ese modo, mediante estas críticas los reformistas alentaron la formación de un nuevo perfil de estudiante que se caracterizaba por un doble compromiso, por un lado, hacia la reivindicación de un proceso de cambio social (para el que formularon un discurso estudiantil que enfatizaba en ideales de emancipación de la Humanidad) y, por otro lado, hacia la democratización las asociaciones estudiantiles y la renovación educativa y científica de la universidad

$\mathrm{Si}$ bien en esta instancia se señalan ciertas posturas restrictivas respecto al ingreso a la universidad, es importante señalar que las mismas no fueran extensivas a todo el reformismo. Asimismo, estas agrupaciones alentaron iniciativas que buscaban reformular el gremialismo de asociaciones estudiantiles mediante implementación de nuevas prácticas electorales, el desarrollo del mutualismo y la promoción de nuevas conductas estudiantiles. Tal como hemos visto, si bien el resultado alcanzado fue en varios casos limitado, estos grupos logran acceder a la conducción de los centros y sus propuestas persisten en agrupaciones de la década siguiente.

De este modo, el estudio de la sociabilidad estudiantil nos permitió analizar la reformulación de prácticas de interacción social que se ponen en circulación en un determinado contexto histórico e institucional. Al mismo tiempo, estas prácticas deben entenderse dentro de procesos de más amplio alcance que en las universidades latinoamericanas se operaban por medio de la ampliación de la matrícula y el acceso de nuevos sectores sociales a la educación superior. En este sentido, si bien el recorte temporal de nuestro estudio se sitúa en un periodo que se inicia entre 1917 y 1918 las propuestas de 
los reformistas porteños en materia de sociabilidad se interpretan en relación a formas de interacción estudiantil que circulaban desde principios de siglo entre los estudiantes de la región.

Por otra parte, la dimensión programática de la sociabilidad, analizada en los discursos de los reformistas, contribuye a comprender cómo se difundían nuevos valores y prácticas estudiantiles dentro y fuera de la universidad. Finalmente, el análisis de las modalidades de interacción social en la vida cotidiana estudiantil, nos permitió estudiar en esa escala las identidades que se construyen y, al mismo tiempo, los conflictos y tensiones al interior del movimiento estudiantil. En este sentido, las críticas de las agrupaciones analizadas ponen en relieve las tensiones y las diferencias existentes dentro del alumnado de la época en su adhesión al reformismo al tiempo que complejizan la compresión de este movimiento. De este modo, al profundizar en las dinámicas que relacionaban a los distintos grupos de estudiantes y en los valores compartidos que en ellos circulaban consideramos que el estudio de la sociabilidad contribuye a aportar otros elementos en la comprensión de los movimientos estudiantiles desde su acción colectiva.

\section{Bibliografía}

\section{Fuentes primarias impresas}

-Belbey, José, “Graves Rumores”, La Cureta, año I, nº4, Buenos Aires, 1918, 73- 75.

-Belbey, José, "Los remansos. (Ensayos sin pretensiones)", La Cureta, año II, nº 9, Buenos Aires, 1919, 66-69.

-Belbey, José, "Palabras de un Compañero", La Cureta, año III, n 14, Buenos Aires, 19821, 248251.

-Belbey, José, "El desbarajuste en el centro", La Cureta, año III, n 15, Buenos Aires, 1921, 280281.

-Bosch, Raimundo, "Nuestras asociaciones estudiantiles", Revista del CMA-CEM, año XIX, nº 212, Buenos Aires, 1919, 375- 385.

-Bullrich, Eduardo, "Memoria del Centro de la presidencia Bullrich", Themis, año XI, no 70, Buenos Aires, 1918, 155- 174.

-Fernández Ríos, Roberto, “Cosas que nos aburren”, La Cureta, año II, nº 11, Buenos Aires, 1919, 144- 145.

-Fray Quimeras, "Pequeñas y grandes cosas. Un cartel”, Themis, año, XI, n 73, Buenos Aires, 1919, 191-193.

-Gallina Rolli, Eugenio, “A la caza de marido", Clarin, año I, no 11, Buenos Aires, 1920, s/p.

-Loudet, Osvaldo, "Memoria del CMA- CEM. Periodo 1914-1915", Revista del CMA-CEM, año XV, no 165- 166, Buenos Aires, 1915, 572-588.

-Migone, Raúl C., "El caso del Dr. Osvaldo Piñero", Themis, año XI, no 71, Buenos Aires, 1918, 156- 160.

- Monner Sans, José María, "Todos somos reformistas", Ideas, año IV, no 19-20, Buenos Aires, 1918, 69-70.

-Muñoz Montoro, Gonzálo, [Reseña de] Bott, Ernesto "Las condiciones contra la lucha de la trata de blancas", Revista del Centro de Estudiantes de Derecho, año XI, nº 66, Buenos Aires, 1917, 629630. 
-Muñoz Montoro, Gonzálo, "La colación de grados”, Themis, año XI, no 72, Buenos Aires, 1918, 5-6.

- Pozzo, Horacio, “El triste 'caso' del Dr. Dellepiane”, Ideas, año IV, no 19- 20, Buenos Aires, 1918, 71- 75 .

- Publicaciones del Ateneo del CMA y CEM, n 5, Buenos Aires, 1921.

- Puente, J, "El ingreso a la Facultad”, La Cureta, año I, nº1, Buenos Aires, 1918, 15-16.

- S.n., "Hechos condenables", La Cureta, año I, nº 6, Buenos Aires, 1918, 144-147.

- S.n., "Manifiesto del Ateneo Universitario. La Reforma Universitaria", Clarín, año I, nº 6, Buenos Aires, 1918.

- S.n., "La moda", Bases, año I, no 1, Buenos Aires, 1919, 2.

-S.n. "Relación oficial del Primer Congreso internacional de Estudiantes Americanos, Evolución, t. III, año III, $\mathrm{n}^{\circ}, 21,22,23$ y 24, marzo- junio, Montevideo, 1908.

-S.n., "Relación oficial del segundo Congreso Internacional de Estudiantes Americanos celebrado en Buenos Aires de 9 a 16 de julio de 1910", Buenos Aires, Tall. Gráf. de la Penitenciaría Nacional, 1912.

- S.n., "Por el laboratorio de histología", La Cureta, Año I, no 4, Buenos Aires, 1919, 72

- S.n., "El desbarajuste en el centro", La Cureta, año III, n 15, Buenos Aires, 1921, 21.

-Solari, J. Antonio, "La acción de los centros", Bases, año 1, nº 1, Buenos Aires, 1918, 1.

-Urcelay, Reinaldo, "Cátedras y ayudantes", La Cureta, año II, no 8, 1918, 42-43.

-Vargas, Hernán, "Ejemplo de la juventud Cordobesa”. La Cureta, año I, n 5, Buenos Aires, 1918,116- 118.

\section{Bibliografía secundaria impresa}

- Agulhon, Maurice, La sociabilidad como categoría histórica. En Formas de sociabilidad en Chile 1840-1940. Santiago de Chile, Fundación Mario Góngora, 1992, 1-10.

- Álvarez Aragón, Virgilio, Conventos Aulas y trincheras. Universidad y movimiento estudiantil en Guatemala. Vol. 1, Guatemala, FLACSO, 2002, 143- 148.

-Ansolabehere, Pablo, "La vida bohemia en Buenos Aires (1880-1920): lugares, itinerarios y personajes" Bruno, Paula (dir.) Sociabilidades y vida cultural. Buenos Aires, 1860-1930, Buenos Aires, Universidad Nacional de Quilmes, 2014, 155- 165.

-Barrancos, Dora, Mujeres en la Sociedad Argentina. Una historia de cinco siglos. Buenos Aires, Sudamericana, 2010.

-Bergel, Martín, “América Latina, pero desde abajo. Prácticas y representaciones intelectuales de un ciclo histórico latinoamericanista. 1898-1936, Cuadernos de Historia, $\mathrm{n}^{\mathbf{o}}$ 36, junio 2012, Universidad de Chile, 7-36.

-Biagini, Hugo E., La contracultura juvenil. De la emancipación a los indignados, Buenos Aires, Capital Intelectual, 2012.

-Bisso, Andrés, Sociabilidad, Política y movilización: cuatro recorridos bonaerenses 1932-1943, Buenos Aires, Buenos Libros, 2009.

-Bourdieu, Pierre, "La juventud no es más que una palabra”, Sociología y cultura, México, Grijalbo, 1990.

-Buchbinder, Pablo, ¿Revolución en los claustros? La Reforma universitaria de 1918, Editorial Sudamericana, Buenos Aires, 2008.

-Bustelo, Natalia, La reforma universitaria desde sus grupos y revistas. Una reconstrucción de los proyectos y las disputas del movimiento estudiantil porteño de las primeras décadas del siglo XX 
(1914-1928). (Tesis de doctorado inédita). Facultad de Humanidades y Ciencias de la Educación. Universidad Nacional de La Plata, 2015.

-Bustelo, Natalia "La juventud universitaria de Buenos Aires y su vínculo con las izquierdas en los inicios de la Reforma Universitaria (1914-1922)", Revista Izquierdas, 16, Santiago de Chile, 2013, $1-30$.

-Calderari, María y Funes, Paula, Escenas reformistas, La reforma universitaria 1918-1930. Buenos Aires, Eudeba, 1998.

-Canaro, Francisco, "Los Bailes del Internado", Canaro, F., Mis Memorias. Mis bodas de oro con el tango, Buenos Aires, Corregidor, 1999.

-Chiroleu, Adriana, "La Reforma Universitaria", Falcón, Ricardo (dir.) Nueva Historia Argentina. Democracia, conflicto social y renovación de ideas, Buenos Aires, Sudamericana, 2000, 357- 389.

-García, Susana, “Embajadores intelectuales'. El apoyo del Estado a los Congresos de estudiantes americanos a principios del siglo XX”, Estudios Sociales, año, X, nº 19, Santa Fe, 2000, 65- 84.

-Graciano, Osvaldo, Entre la torre de marfil y el compromiso político. Intelectuales de izquierda en la Argentina, 1918- 1955, Bernal, UNQ, 2008.

-Graciano, Osvaldo, "El Partido Socialista de Argentina: su trayectoria histórica y sus desafíos políticos en las primeras décadas del siglo XX", A Contra Corriente. Una revista de historia social y literatura de América Latina, vol. 7, n³, Raleigh, 2010, 1- 37.

-Hall, Stuart, "Introducción: ¿quién necesita una identidad?”, Hall, Stuart y Paul du Gay, Cuestiones de identidad cultural, Buenos Aires, Amorrortu, (2003) [1996], 13-39.

- Halperín Donghi, Historia de la Universidad de Buenos Aires, Buenos Aires, Eudeba, 2012, [1962].

- Landinelli, Emilio, El movimiento estudiantil en el Uruguay. Primera parte. De los orígenes a la conquista de la Ley Orgánica de 1958. México, FLACSO, 1983.

-López, María Pía, Hacia una vida intensa: una historia de la sensibilidad vitalista, Buenos Aires, Eudeba, 2010.

-Losada, Leandro, La alta sociedad en la Buenos Aires de la Belle Époque, Buenos Aires, Siglo XXI, 2008.

- Machuca Becerra, Roberto, América Latina y el Primer Congreso de estudiantes de 1921, tesis de licenciatura, México, UNAM, 1996.

- Markarian, Vania, Jung, María Eugenia, Wschebor, Isabel, 1918. Una hora americana. Vol II, Universidad de la República, 2008.

-Milanesio, Natalia, "Gender and Generation: The University Reform Movement in Argentina, 1918”, Journal of Social History, vol 39, n 2, 2005, 505-529.

-Navarro Navarro, Javier, "Sociabilidad e historiografía: trayectorias, perspectivas y retos", Saitabi, 56, Valencia, 2006, $99-119$.

-Portantiero, Juan Carlos, Estudiantes y política en América Latina. El proceso de la reforma universitaria (1918 -1938), México, Fondo de Cultura Económica, 1978.

-Sabato, Hilda, "Estado y sociedad civil”, Elba Luna y Elida Cecconi (coord.). De las cofradías a las organizaciones de la sociedad civil. Historia de la iniciativa asociativa en la argentina 17761990, Argentina, Edilab, 2012, 101- 170.

-Van Aken, Mark, Los militantes. Una historia del movimiento estudiantil universitario uruguayo desde sus orígenes hasta 1966, Montevideo, Fundación cultura universitaria, 1990.

- Van Aken, Mark, "University Reform before Córdoba", Hispanic American Historical Review, vol. 51, nº. 3, 1971, 447-462.

-Vommaro, Pablo, Juventudes y políticas en la Argentina y en América Latina. Tendencias, conflictos y desafios, Grupo Editor Universitario, Buenos Aires, 2015. 


\section{Fuentes electrónicas}

- Javier Escalera, "Sociabilidad y relaciones de poder", Kairos, Universidad Nacional de San Luis, año 4, no 6, 2000. Disponible en: http://www.fices.unsl.edu.ar/ kairos/k06-02.htm

- Fuentes, Sebastián- Gerardo, "Un club para "nosotros" en la reforma del 18. Sentidos de la universidad y la nación en lo jóvenes universitarios no reformistas", Revista iberoamericana de Educación Superior (RIES), vol. VII, no 18, México, UNAM_ISSUE/Universia, 2016, 60-81. Disponible en: file:///C:/Users/MArio/Downloads/1152-5329-3-PB\%20(1).pdf

-González Bernaldo de Quirós, Pilar, "La sociabilidad y la historia política", Nuevo Mundo Mundos Nuevos, 2008. Disponible en: http://nuevomundo.revues.org/24082.

-Martín Criado, Enrique "Generación/Clase de edad”, Román Reyes (Dir.) Diccionario Crítico de Ciencias Sociales, Madrid y México, Ed. Plaza y Valdés, 2009. Disponible en: http://www.ucm.es/info/eurotheo/diccionario/G/generaciones.htm 